LR

58,6

414

Received 1 October 2008 Reviewed 5 January 2009

Revised 30 January 2009

Accepted 2 February 2009

\section{A writing support programme for Irish academic librarians}

\author{
Helen Fallon \\ National University of Ireland Maynooth, Maynooth, Ireland
}

\begin{abstract}
Purpose - The purpose of this paper is to explore the benefits of a writing support programme in developing the skills and motivation of librarians to write for academic publication.

Design/methodology/approach - A brief review of the literature is presented. The model developed and implemented by this author is outlined. Findings from a survey of participants are discussed.

Research limitations/implications - The formal programme commenced in 2007. The publication process takes time, particularly in the case of peer-reviewed journals. This is exploratory work. It will take time to build up a body of information and a community of librarians writing for publication. Initial evidence indicates there is significant value to the programme.

Practical implications - The model is transferable and could help in building skills and confidence in academic writing. In addition academic writing could serve as a bridge between lecturing and library staff, addressing issues of common concern across the Academy.

Originality/value - This is the first formal writing support programme for librarians in Irish universities. Models exist in the USA. A similar model is used in the UK and Ireland to support lecturing staff writing for publication.
\end{abstract}

Keywords Librarians, Authorship, Serials, Skills training, Ireland, Northern Ireland

Paper type Case study

\section{Introduction}

Writing for publication is an accepted and expected part of the role of lecturing staff in Irish universities. No such recognition of the librarian as an academic writer exists. Many Irish librarians are actively involved in local and national working groups dealing with the major library issues of the day. They regularly present at national and international conferences, conduct local and national surveys and engage in a range of interesting and innovative practice and research-related activities. Despite this wealth of knowledge, skills and experience, very few Irish academic librarians publish in the peer-reviewed literature. There may be a certain paradox in that while librarians support and promote scholarship across all disciplines, they are generally not actively encouraged to see writing and creating the literature of these disciplines as part of their role within the University.

Against this background, this paper explores the benefit of a formal writing support programme offered by this author to library staff, through the Academic and National Library Training Co-operative (ANLTC). This collaborative training body provides short courses to the library staff of the seven university libraries in the Irish Republic, the Dublin Institute of Technology, Royal College of Surgeons in Ireland, National Library of Ireland, Queen's University of Belfast and University of Ulster. Further information on ANLTC is available at www.anltc.ie

While, the programme was offered to library staff at all grades, for consistency I use the term librarian throughout this paper.

Library Review

Vol. 58 No. 6, 2009

pp. $414-422$

(C) Emerald Group Publishing Limited 0024-2535

DOI $10.1108 / 00242530910969776$

\section{Context/background}

There are seven universities, 14 Institutes of Technology and number of other public and private higher education institutions in the Republic of Ireland. The Higher 
Education Authority (HEA) gives the figure for students in public funded higher education institutions for the year 2006 as 153,606 (HEA, 2008). Institutions are comparatively small by international standards and there is substantial crossinstitutional library co-operation.

One Irish institution, University College Dublin, has an academic department of information and library studies. Postgraduate diplomas, master's and doctoral programmes are offered. Approximately 60 students graduate with either a postgraduate diploma or a master's degree each year. Those undertaking the master's programme complete a research methodology course and submit a thesis. It should be possible to convert or develop such theses into journal articles. However, the absence of formal support on finishing the programme, such as that offered by the thesis supervisor, may act as a deterrent. In the Irish library environment there is a dearth of senior library staff who are actively publishing in peer-reviewed journals to act as role models. These factors, alongside the challenge of adjusting to their first professional post, may discourage the new librarian from engaging in academic writing.

Sconul Focus is the most popular publishing outlet for Irish academic librarians. The single Irish journal of librarianship An Leabharlann: The Irish Library, published by the Library Association of Ireland and the Chartered Institute of Library and Information Professionals Ireland, has recently been revitalised. It is published twice a year and should offer a much-needed Irish publishing outlet for both academic and public libraries.

Recently, ANLTC introduced an award that aims to promote and support research by librarians in member libraries. A total of $€ 2,000$ is given to a librarian to undertake a piece of research that will be of benefit to all ANLTC-member libraries. It is too early as yet to assess the impact of the award.

Against this background, this paper explores the benefit of a formal writing support programme to develop skills and motivation to write among Irish librarians.

\section{Literature review}

The literature relating to librarians writing for publication falls into three categories. The first offers practical advice and guidance, the second describes output and the final category deals with writing interventions/support and the promotion of librarians as academic writers. This one review will deal with all three categories briefly.

\section{Literature offering practical guidance}

Gordon's The Librarian's Guide to writing for Publication (2004a) covers the steps in the publishing process and the requirements in writing for various types of publications. Elsewhere, she provides useful tips for the new writer including ideas generation and handling rejection (2004b). Flatley and Weber (2004) offer a wide range of practical tips on publishing including book and website reviews and writing articles and books.

They include a useful resource list. Joint (2003) provides guidance to librarians new to publishing. In a later article Joint (2006) argues that academic writing and professional development are related activities.

The booklet How to Get Published in LIS Journals: A Practical Guide (2003) provides a range of short practical articles. These include Hernon's exploration of the peer review process; Hinchliffe's advice on preparing and presenting a manuscript to a publisher; Searing's five questions to ask when selecting a journal and Walter's advice on developing presentations into publishable articles.

These sources provide useful guidance and can be supplemented with a wide range of books and articles that while not specifically aimed at librarians, provide

\section{Writing support programme}


LR 58,6

416 information on academic writing that crosses disciplines and practice (Huff, 1999; Rankin, 2001; Luey, 2002; Henson, 2005; Kitchin and Fuller, 2005; Murray, 2005; Canter and Fairbarn, 2006; Day, 2007; Maimon, 2007).

\section{Literature relating to publishing patterns of academic librarians}

Some studies of publication patterns of practicing academic librarians have been undertaken in the USA (Krausse and Sieburth, 1985; Watson, 1985; Budd and Seavey, 1999; Weller et al., 1999).

Overall, the literature suggests that the majority of those who publish tend to be from large universities where scholarly research and publication are important elements of the institutional culture. While publishing output is higher among those seeking tenure and those in tenure-track positions, Bede Mitchell and Reichel (1999) found, in their study of scholarly requirements for tenure, that while the majority of institutions with tenure-track librarians do require evidence of scholarship for tenure, the amount varied greatly and the requirement for scholarship does not appear to have been a major impediment to progressing to tenure.

\section{Literature relating to writing interventions/writing support}

The recognition that productive writing requires support has led to the development of interventions to support librarians in their academic writing at the University of Buffalo and Texas A\&M University.

Tysick and Babb (2006) examine an academic writing group for junior faculty librarians established at the University of Buffalo, in 2002. Following a two-day writing retreat an information session was held, where goals and objectives were agreed. At this session, the group received advice from senior librarians and were provided with a copy of Elizabeth Rankin's The Work of Writing. The group held bimonthly one-hour meetings. Members submitted writing for review before each meeting. Participants were provided with guidelines on giving feedback. Two submissions per session were critiqued by the group, with 20 min of feedback for each submission, followed by $20 \mathrm{~min}$ for news and open discussion. An electronic discussion list was established and details of publishing opportunities forwarded. Collaboration was actively promoted, with publishers and editors invited to address the group.

The writing group expanded into a system of peer monitoring, helping new librarians become assimilated into the academic culture. The value, Tysick and Babb concluded, went beyond the original objective of promoting academic writing and research.

Miller and Benefiel (1998) examine the support group as a strategy for success among academic librarians seeking tenure at the Sterling C. Evans Library at Texas A\&M University. They note librarians face hurdles not encountered by lecturing staff, in that they generally have not received extensive training in research methodology, have less flexibility regarding writing during work time and less access to research funds. Topics covered by the tenure support group include advice on presenting posters at conferences, guidance on obtaining university research funds and training on statistical analysis. The group also provides an opportunity for members to discuss projects, proofread and critique the work of others and identify potential collaborators. As in the case of the University of Buffalo, Miller and Benefiel found the value of the group went beyond the original concept of helping those seeking tenure, acting as a support for a wide variety of professional development including publishing and presenting at conferences. 
This is the first exploration of a support programme for academic librarians in an Irish context. Research on the value of writing interventions for lecturers in Irish universities, has been carried out by Sarah Moore, from the University of Limerick. She suggests that the provision of the facilitated environment of a writers' retreat may have the potential to impact on the writing habits of academics. Noting the limited research on the nature of academic writing, Moore (2003) emphasizes the importance of further investigation.

The ANLTC writing programme

The one-day Introduction to Writing for Academic Publication course was first offered as part of the 2007 ANLTC programme. This was the first academic writing course specifically for library staff offered in Ireland. Fourteen people, from six of the seven university libraries in the Republic of Ireland, attended. Twelve of the 14 were employed at various librarian grades; two were employed as library assistants. The course was designed and facilitated by this author.

It was designed as a single-day event. However, in the light of expressed needs, two follow-on days were offered, four and eight months after the initial workshop.

\section{Workshop (day 1)}

The workshop followed the following format:

(1) Session 1. Exploring motivation to write and getting started.

(2) Session 2. Experiences of academic writing.

(3) Session 3. Generating ideas.

(4) Session 4. Structuring an article.

(5) Session 5. Identifying the journal/publishing outlet.

(6) Session 6. Writing the article.

(7) Session 7.Submission.

(8) Session 8. Peer-review \& resubmission.

(9) Session 9. Creative ways of overcoming obstacles and getting support.

(10) Session 10. Drawing up a writing plan.

Reasons for attending the programme included finding the motivation to write, getting tips on the discipline of writing and developing the confidence to write. Specific goals included learning how to craft articles from a thesis and gaining an understanding of the publishing process. People felt this is a time of great change and activity in libraries and there is the potential to write about interesting topics.

Participants were then asked to write for five minutes, in sentences not bullets, without stopping, to a prompt. Prompts included:

- A really interesting project I'm involved in that I think people would be interested in reading about is ...

- Something I know quite a lot about and would be interested in writing about is. .

- Through writing, I'd really love to examine. . .

This was followed by a one-hour session, where four guest speakers, librarians who had already published, shared their experiences of publishing in the following areas professional journal; peer-reviewed journal; a chapter in an edited collection and

\section{Writing support programme}


LR 58,6

418 crafting an article from a piece of writing originally created for a different purpose (in this case a thesis). This session helped to demystify the writing process. Participants learned from the experiences of their peers, both in terms of the writing and the publishing process.

The clustering technique described by Maimon (2007) which involves working from a central circle (main topic) and linking to subtopics, formed the basis of the section on ideas generation.

Structuring dealt with both peer-reviewed and professional journal articles.

The following outline, adapted from Kitchin and Fuller (2005) was suggested for a peer-reviewed journal article. Participants drew up an outline adapting this as appropriate.

Title - This should include words that indicate the key theme of the article. If a subtitle is used, it should indicate the specific focus or argument.

Abstract - This is a synopsis, not an introduction to the article. It should detail the essence of the article - its main arguments and findings - in clear and unambiguous terms, so that a potential reader knows what to expect.

Introduction - This introduces the substantive content of the paper. It sets the scene and provides the reader with an insight into what is to follow. Normally it moves from the general to the specific.

Literature Review - The literature review should be highly selective and specific, referring to the work most relevant to the case being made. It should demonstrate that the author is familiar with thinking/debate around the topic.

Methodology/Approach/Conceptual Framework - This explains how the study was undertaken. It should detail exactly how any data were generated and the specific techniques used.

Analysis/Results - This should state clearly what the findings are and how they are being interpreted.

Discussion - This folds together the previous sections, linking the findings from the research, the literature review and the author's own thinking on the topic.

Conclusion - The conclusion draws the article to a close by summarising the rationale and findings, reaffirming the value of the research and suggesting how it might be developed further.

References - This provides the references for material cited. It should follow the journal guidelines on citation style.

Practical exercises allowed participants time to draw up an outline for an article, to begin writing sections, to formulate a working title and abstract and to consider where they might submit the piece. Participants were encouraged to write and had the opportunity to discuss their ideas with colleagues, throughout the day. While the peerreview process was explained, the value of publishing in non-peer reviewed journals and presenting at conferences as a starting point for publication, was stressed. The emphasis was on encouraging people to write. More details on the techniques and methodologies used can be found in Fallon (2009).

The one-day session concluded with participants being encouraged to continue their writing with a view to having a follow-on day later in the year.

\section{Peer-review session 1}

Following the initial workshop, participants were invited to attend a follow-on day four months later. The purpose of the day was to give and receive feedback on writing and to share experiences. Those wishing to participate were asked to submit an abstract of 
a paper or a short description of another piece of writing to this author. Eight of the original 14 participants opted to submit. Pairs were established on the basis of putting people from different institutions together. One month prior to the peer-review day, the pairs exchanged completed first drafts.

On the actual day only six of the eight were able to attend. Following some initial "writing to prompt" exercises, designed to get people into academic writing mode, participants were provided with guidelines on giving feedback. Each pair worked together for two hours. This was followed by an open session where participants had an opportunity to discuss their writing and share ideas and experiences.

The group of six agreed to continue working on their drafts, to keep in contact with their "writing buddy" and to reconvene in four months with a finished article.

\section{Peer-review session 2}

On the third and final day, the editor of a peer-reviewed journal facilitated a question and answer session. This was particularly useful, as people were finishing articles and actively planning to submit to journals.

The remainder of the session was taken up with the further exchange of feedback between "writing buddies" and the group sharing writing experiences.

\section{Evaluating the process}

One year after completing the initial one-day workshop, the 14 original members of the group were asked to complete a questionnaire. Ten responded.

- one had published a book review;

- three had either published or had articles accepted for publication by peerreviewed journals;

- three had either published or had articles accepted for publication in professional journals; and

- one had made significant progress.

Eight of the ten respondents to the questionnaire reported that the writing programme had a strong impact on their writing giving them confidence and a better understanding of publishing processes and the actual techniques of writing. Two reported that it had little impact and four of the 14 initial participants did not complete the questionnaire.

Insights gained from discussions throughout the programme, feedback from the questionnaire, ideas gleaned from a review of the literature and my own views as both the presenter of the programme and an academic writer (this paper was drafted throughout the programme and I was an active participant in the peer-feedback sessions) form the basis of the discussion and conclusion.

\section{Discussion}

Issues emerging from the process include the benefits of a structured programme, the value of peer-support, the need to develop a culture of writing and the need for more local support for academic writing.

Survey respondents identified clear benefits to participation in a structured programme. This included having dedicated time to learn about the mechanics of writing.

It's not in fact an arcane discipline, just need the tricks and tools to do it and that first session [day 1] covered many of those aspects 
LR 58,6

420
Having some dedicated time away from everything so that I could clearly focus on my writing was a great help.

The peer-support group and the follow on sessions offered valuable ongoing support. Participants gained knowledge of the research process by reading the work of others, providing feedback and participating in discussion.

The formula was good, i.e. that the piece was e-mailed ahead, so that each could read the other's work. This session [day 2] was very useful, as the piece was viewed from a fresh perspective, and suggestions for development offered and accepted. I felt this helped build trust.

The value of "readers" should not be underestimated, as the acknowledgements in most academic texts recognise, when numerous people are thanked for reading the work "in draft form”. The expectation that writing partners are in frequent touch might also be useful, and speed the process along.

The peer support brought my article from 40 per cent to 80 per cent ready for submission for publication.

The value of the peer-support group went beyond giving feedback and was effective in counteracting isolation.

Knowing that you are not alone when trying to get writing done - writing can be quite isolating.

The most useful aspect was the conversations, hearing other librarians' experiences, and being imbued with a sense of can do.

It was recognised that, taking this a step further, there is a need to develop a culture of writing among librarians.

What is lacking I think is a culture where we are expected to share the findings of our work with others. The culture of presenting is growing, but for others to benefit from that they need to attend the relevant conferences. It would really help the profession to grow, if it could become the norm to write papers reporting projects, initiatives, etc. The first step might be to make it the norm to publish proceedings of the Irish University Information Systems Colloquium and the Irish National and University Libraries Staff conference. The lack of something like an Irish Journal of Academic Librarianship is also a hindrance. I think people might feel more confident to submit papers to an Irish journal.

Wonderful idea. Lack of an in-depth pool of academic writers in Ireland and I suspect once the process gathers momentum more staff will get involved. I think the key constraints are that it is not on as many staff's radar as a possible part of their job, or a useful career development tool, and the lack of role models [is also an issue].

While the academic writing programme brought together library staff from a number of different libraries, it was felt that more could be done in individual institutions to support and promote academic writing.

Peer-support sessions \& writing clinics held in our individual institutions on a regular basis.

Management support - in motivating staff to think of how projects can become published articles and encouraging staff to write.

Liaising with one's local promotions boards to discuss the role of writing as one of the "key" factors in gaining promotion.

Informally among colleagues over a writing email list.

Some form of reward for publication - an annual prize for writing - within an institution. 
The feedback from participants supports the literature findings which suggest that writing support programmes can help develop the confidence, skills and motivation to write.

Insights gained from the process and the subsequent feedback will be used to further develop the academic writing programme.

\section{Conclusion}

Academic publication among librarians needs to be further explored as a valid form of professional development and a means of enhancing individual and institutional profiles. Generally librarians writing must do so outside of work, with little or no formal support. There is also no obvious benefit in career terms for librarians who do write. Irish universities have recently introduced Performance Measurement Development Systems (PMDS). Academic writing could be formally highlighted by libraries during the PMDS process. One Irish university has introduced a professional promotion scheme, which is portfolio based. Here evidence of having published might be of direct benefit to career progression.

Academic writing can promote the visibility of the library within the Academy. It offers the opportunity to share and disseminate experience, skills and practice that don't exist in the same framework elsewhere in the University, including a knowledge of collections, copyright, digitization, information sources and information literacy. The sharing and dissemination of experiences, skills and practices can assist in bringing about change both at the library level and at the university level. Librarians share common concerns and objectives with people outside the library, including concerns for student support, research support and the positioning of the University both nationally and internationally. Writing offers a bridge between librarians and faculty to achieve strategic objectives.

As librarians become more involved in information literacy initiatives and working with lecturing staff in designing information literacy programmes and in supporting research, more opportunities for collaborative publishing will emerge. Writing with academics, education developers and policy makers has the potential to open up new dialogues, new partnerships and new ways of seeing and thinking. Merging disciplines and examining common issues from different points of view, in addition to being energizing and creative, may help create new knowledge.

This article is based on a programme begun in May 2007 and evaluated in 2008. The publication process itself can be lengthy, particularly in the case of peer-reviewed journals. It will take time to develop a community of librarians writing for publication and to build up a body of data for more detailed analysis. The programme is now entering its third year. Evidence to date is very positive and indicates that there is a strong value to the programme.

\section{References}

Budd, J.M. and Seavey, C.A. (1990), "Characteristics of journal authorship by academic librarians", College and Research Libraries, Vol. 51, pp. 463-70.

Canter, D. and Fairbarn, G. (2006), Becoming an Author: Advice for Academics and Other Professionals, Open University Press, Maidenhead.

Day, A. (2007), How to Get Research Published in Journals. Ashgate, Burlington, VT.

Fallon, H. (2009), "The academic writing toolkit: writing for professional and peer-reviewed journals", Sconul Focus, No. 45, Spring, pp. 66-71.

Flatley, R.A. and Weber, M.A. (2004), "Perspectives on. . .professional development opportunities for new academic librarians”, Journal of Academic Librarianship, Vol. 30 No. 6, pp. 488-92.

Writing support programme 
LR 58,6

422
Gordon, R.S. (2004a), The Librarian's Guide to Writing for Publication, Scarecrow, Lanham, MD.

Gordon, R.S. (2004b), "Getting started in library publication: advice on finding your place in library literature”, American Libraries, Vol. 35 No. 1, pp. 66-9.

Henson, K.T. (2005), Writing for Publication, Pearson, Boston, MA.

Hernon, P. (2003), "Peer review", How to Get Published in LIS Journals: A Practical Guide, Elsevier/Library Connect, Pamphlet 2, p. 6.

Hinchliffe, L.J. (2003), "Seeking to publish? prepare for success!", How to Get Published in LIS Journals: A Practical Guide, Elsevier/Library Connect, Pamphlet 2, p. 3.

Huff, A.S. (1999), Writing for Scholarly Publication, Sage, London.

Ireland. Higher Education Authority (2008), Higher Education: Key Facts and Figures. Higher Education Authority, Dublin, pp. 14-5.

Joint, N. (2003), “Writing for publication in a library journal”, SCONUL Newsletter, Vol. 28, pp. 61-6.

Joint, N. (2006), "Enhancing professional development by writing for publication in library and information science”, Library Review, Vol. 55 No. 1, pp. 5-7.

Kitchin, R. and Fuller, D. (2005), The Academic's Guide to Publishing, Sage, London.

Krausse, S.C. and Sieburth, J.F. (1985), Patterns of authorship in library journals by academic librarians", Serials Librarian, Vol. 9, Spring, pp. 127-38.

Luey, B. (2002), Handbook for Academic Authors, 4th ed., Cambridge University Press, Cambridge.

Maimon, E.P. (2007), A Writer's Resource: A Handbook for Writing and Research, 2nd ed., McGraw-Hill, Boston, MA.

Miller, J.P. and Benefiel, C.R. (1998), "Academic librarians and the pursuit of tenure: the support group as a strategy for success", College \& Research Libraries, Vol. 59 No. 3, pp. 1-6.

Mitchell, W.B. and Reichel, M. (1999), "Publish or perish: a dilemma for academic librarians", College and Research Libraries, Vol. 60 No. 3, pp. 232-43.

Moore, S. (2003), "Writers' retreats for academics: exploring and increasing the motivation to write", Journal of Further and Higher Education, Vol. 27 No. 3, pp. 333-42.

Murray, R. (2005), Writing for Academic Journals, Open University Press, Maidenhead.

Rankin, E. (2001), The Work of Writing: Insights and Strategies for Academics and Professionals, Jossey-Bass, San-Francisco, CA.

Searing, S.E. (2003), "Questions to ask when selecting a journal", How to Get Published in LIS Journals: A Practical Guide, Elsevier/Library Connect, Pamphlet 2, p. 4.

Tysick, C. and Babb, N. (2006), "Perspectives on writing support for junior faculty librarians: a case study," Journal of Academic Librarianship, Vol. 32 No. 1, pp. 94-100.

Watson, P. (1985), "Production of scholarly articles by academic librarians and library school faculty", College \& Research Libraries, Vol. 46, pp. 334-42.

Weller, A.C., Hurd, J.M. and Wiberley, S.E. (1999), "Publication patterns of U.S. academic librarians from 1993 to 1997”, College \& Research Libraries, Vol. 60 No. 4, pp. 352-62.

\section{Further reading}

Walker, S. (2003), "Writing from presentations”, How to Get Published in LIS Journals: A Practical Guide, Elsevier/Library Connect, Pamphlet 2, p. 7.

\section{Corresponding author}

Helen Fallon can be contacted at: helen.b.fallon@nuim.ie

To purchase reprints of this article please e-mail: reprints@emeraldinsight.com Or visit our web site for further details: www.emeraldinsight.com/reprints 